УАK 342.55:658.310.9

ББК $67.400 .7+65.291 .6$

DOI 10.22394/1682-2358-2019-6-18-26

N.S. Gegedyush, Candidate of Sciences (Sociology), Head of the Public Administration Department, Povolzhsky Institute of Management named after P.A. Stolypin, Branch of the Russian Presidential Academy of National Economy and Public Administration

E.A. Mamlina, Candidate of Sciences (Sociology), Docent of the Public Administration Department, Povolzhsky Institute of Management named after P.A. Stolypin, Branch of the Russian Presidential Academy of National Economy and Public Administration

\section{HUMAN RESOURCE POTENTIAL OF LOCAL GOVERNMENTS OF THE SARATOV REGION}

Quantitative and qualitative indicators of the personnel potential of the municipal service for 2016-2018 are analyzed. The experience of the Saratov region in introducing innovative approaches to improving the level of professionalism and competence of municipal servants is considered. Recommendations aimed at providing training opportunities for municipal servants with the use of distance learning technologies are developed.

Key words and word-combinations: personnel potential, personnel structure, local authorities.
Н.С. Гегедюи, кандидат сочиологиеских наук, заһедуюший кафедрой государственного и муниципального упраһления Поволжского института управления имени П.А. Стольтина филиала Российской академии народного хозяйстьа и государственной службь при Президенте РФ (email: gegedush@rambler.ru)

E.A. Мамлина, кандидат соииологических наук, дочент кафедрь государственного и мунииипального управления Поволжского института управления имени П.А. Стольпина филиала Российской академии народного хозяйства и государственной службъ при Президенте РФ (mamlina2010@yandex.ru)

\section{КААРОВЫЙ ПОТЕНЦИАА ОРГАНОВ МЕСТНОГО САМОУПРАВ АЕНИЯ В САРАТОВСКОЙ ОБААСТИ}

Аннотациия. Проводится анализ показателей кадрового потенциала муниципальной службы в Саратовской области в 2016-2018 г. Рассмотрен опыт Саратовской области по внедрению инновационных подходов к повышению уровня профессионализма и компетенции муниципальных служащих. Обоснованы и сформулированы рекомендации, направленные на обеспечение возможности обучения муниципальных служащих на рабочих местах с применением дистанционных образовательных технологий.

Ключевые слова и словосочетания: кадровый потенциал, кадровый состав, органы местного самоуправления.

P азграничение предметов ведения и полномочий межАУ органами госуАарственной власти Российской ФеАерации, государственными органами субъектов РФ и органами 
местного самоуправления установлено таким образом, что многие вопросы функционального обеспечения условий проживания населения решаются органами местного самоуправления. В связи с этим многие российские исследователи муниципального управмения обосновывают прямое вцияние каАрового потенџиала органов местного самоуправления на уровень социально-экономического развития муниципальных образований и необходимость разработки стратегии совершенствования каАрового состава муниципальной службы [1; 2]. Сохранение и развитие каАрового потенциала муниципальных служащих, повышение компетентности и профессионализма преАставителей органов местного самоуправления входят в число базовых условий развития муниџипальной служкбы в регионе. Средством определения уровня кадрового потенциала муниципальных служкащих выступает проводимый на регулярной основе мониторинг количественных и качественных индикаторов состояния кадров органов местного самоуправления.

С целью выявления особенностей кадрового потенциала органов местного самоуправления Саратовской области проведен анализ сводных данных, представменных муниципальными образованиями по итогам 2018 г. Общее количество муниципальных служащих составило 5059 чел., что на 3,6\% меньше, чем в 2016 г. (5503 чел.) и на 0,6\% меньше численности 2017 г. (5108 чел.). Аинамика комичественного состава служащих региона (табц. 1) связана с укрупнением муниципальных образований и отражкает общероссийскую тенденщию к сокращению численности муниципальных служащих, фиксируемую Росстатом с 2006 г.

Таблица 1

Численность муниџипальных служащих в Саратовской области, чел.

\begin{tabular}{|c|c|c|c|c|c|}
\hline \multirow{3}{*}{ Год } & \multirow{3}{*}{ Всего } & \multicolumn{4}{|c|}{ Типы муниципальных образований } \\
\hline & & \multirow{2}{*}{$\begin{array}{c}\text { Городские } \\
\text { округа }\end{array}$} & \multirow{2}{*}{$\begin{array}{c}\text { Муниципальные } \\
\text { районы }\end{array}$} & \multicolumn{2}{|c|}{ Поселения } \\
\hline & & & & городские & сельские \\
\hline 2015 & 5389 & 1148 & 2948 & 216 & 1077 \\
\hline 2016 & 5248 & 1146 & 2904 & 206 & 992 \\
\hline 2017 & 5108 & 1374 & 2676 & 79 & 979 \\
\hline 2018 & 5059 & 1223 & 2744 & 74 & 1018 \\
\hline
\end{tabular}

При формировании стратегии управления каАрами муниципальной службы анализ возрастных характеристик кадрового состава позволяет, с одной стороны, определить качество организационной культуры и уровень зрелости управленческого аппарата, с Аругой - эффективные формы профессионального развития служащих. В условиях цифровой трансформации публичного управления оџенка возрастных характеристик муниципальных служащих приобретает особый смысл, поскоцьку возраст вцияет на скорость освоения новых электронных систем и технологий, внедряемых в деятельность органов местного самоуправления. По состоянию на 1 октября 2011 г. средний возраст муниципального служкащего по России - 43 года, на 1 октября 2016 г. - 42 года [3]. В Саратовской области этот показатель в 2018 г. составиц 41 год (табц. 2). 
Таблища 2

Возрастной состав мунищипальных служащих в Саратовской области

\begin{tabular}{c|c|c|c|c|c|c|c|c|c}
\hline Год & $\begin{array}{c}\text { Средний } \\
\text { возраст, лет }\end{array}$ & $\begin{array}{c}18-35 \\
\text { лет, чел. }\end{array}$ & $\begin{array}{c}\text { Доля, } \\
\%\end{array}$ & $\begin{array}{c}36-50 \\
\text { лет, чел. }\end{array}$ & $\begin{array}{c}\text { Доля, } \\
\%\end{array}$ & $\begin{array}{c}51-65 \\
\text { лет, чел }\end{array}$ & $\begin{array}{c}\text { Доля, } \\
\%\end{array}$ & $\begin{array}{c}\text { Старше 65 } \\
\text { лет, чел. }\end{array}$ & $\begin{array}{c}\text { Доля, } \\
\%\end{array}$ \\
\hline 2017 & 41 & 1737 & 34 & 2145 & 42 & 1174 & 23 & 52 & 1 \\
2018 & 41 & 1766 & 34,9 & 2125 & 42 & 1164 & 23 & 4 & 0,1
\end{tabular}

В возрастной структуре преобладают служащие в возрасте 36-50 ^ет (42\%), домя служащих в возрасте $18-35$ мет и 51-65 мет составляет $34,9 \%$ и $23 \%$ соответственно. Сотрудники в возрасте свыше 65 мет занимают менее $1 \%$ Аомжностей. Наблюдается незначительный рост доли служащих в возрастной категории до 35 мет, что Аолжно положительно отразиться на показателе в перспективе. Основная доля руководителей муниџипалитетов в Саратовской области в 2018 г. - служашие в возрасте 36-50 кет, а в 2017 г. возрастной диапазон составмял 51-65 мет. Таким образом, отмечается динамика омоложкения руководящего состава мунищипальных образований. Гендерное распределение кадрового состава муниципальных служащих в Саратовской области в 2018 г. демонстрирует преобладание женшин - 81,4\%, что несколько больше по сравнению с показателями 2016 и 2017 гг. (на 2,15 и 0,5\% соответственно) (табл. 3). С повышением уровня должностей муниципальной служжбы доля женщин заметно уменьшается. Следует отметить, что каАровый состав муниципальных служащих Саратовской области не отличается от общероссийской ситуации.

Таблища 3

Гендерный состав муниципальных служащих в Саратовской области

\begin{tabular}{c|c|c|c|c}
\hline Год & Мужчины, чел. & Доля мужчин, \% & Женщины, чел. & Доля женщин, \% \\
\hline 2015 & 1126 & 20,89 & 4263 & 79,11 \\
2016 & 1089 & 20,75 & 4159 & 79,25 \\
2017 & 973 & 19,1 & 4123 & 80,9 \\
2018 & 941 & 18,6 & 4118 & 81,4
\end{tabular}

Распредемение мунищипальных служащих по стажу муниџипамьной службы является более равномерным. Аоля служаших со стажем до 3-х мет составмяет 19\%, со стажкем 10-15 мет и свыше 15 мет - соответственно 22,5\% и 23,5\%, а наибольшая домя служаших со стажем 3-10 ^ет - 35\% (табл. 4).

Таблища 4

Распределение мунищипальных служащих по стажу в Саратовской области, \%

\begin{tabular}{c|c|c|c|c}
\hline \multirow{2}{*}{ Год } & \multicolumn{4}{|c}{ Стаж } \\
\cline { 2 - 5 } & до 3-х лет & $3-10$ лет & $10-15$ лет & свыше 15 лет \\
\hline 2017 & 19,1 & 34 & 20,2 & 26,7 \\
2018 & 19 & 35 & 22,5 & 23,5
\end{tabular}

20 Bulletin of the Volga Region Institute of Administration • 2019. Vol. 19. № 6 
Распредемение глав мунищипальных образований / глав местных администраций по стажу за 2017 и 2018 гг. представлено в табл. 5. В категориях стажа Ао 3-х мет, 10-15 мет и свыше 15 мет отмечается положитемьная динамика.

Таблииа 5

Распределение глав муниципальных образований / глав местных администраџий по стажу в Саратовской области, \%

\begin{tabular}{c|c|c|c|c}
\hline \multirow{2}{*}{ Год } & \multicolumn{4}{|c}{ Стаж } \\
\cline { 2 - 5 } & до 3-х лет & $3-10$ лет & $10-15$ лет & свыше 15 лет \\
\hline 2017 & 19 & 41 & 17 & 23 \\
2018 & 20 & 36 & 19,7 & 24,3
\end{tabular}

Анализ мнений экспертного сообщества позволяет утвержАать, что в ходе реформирования местного самоуправления главные проблемы этого института остаются нерешенными. ОАной из них является недостаточный уровень квалификации и профессионализма муниципальных служащих. Так, в отчете о деятельности в 2018 г. Ассоџиацией сибирских и дальневосточных городов как следствие низкого уровня заработной платы муниципальных служащих отмечен недостаток квалифиџированных кадров, особенно в малых городах и сельской местности [4].

В Саратовской области соотношение муниципальных служаших с высшим и средним профессиональным образованием составляет примерно четыре к одному (80 и 20\% соответственно). Это свидетельствует об устойчивой тенденции повышения образовательного уровня представителей муниципамитетов. При этом Ава и более высших образования в 2018 г. имели 304 служащих, что составляет 6\% от их общего числа. Показатель 2018 г. выше значений 2017 и 2016 гг. - $274(5,4 \%)$ и 289 (5,51\%) служащих соответственно. Положительная динамика отмечается в отношении освоения служащими программ магистратуры: в 2018 г. Аоля служащих, имеющих степень магистра оказалась на 0,5\% больше, чем в 2017 г. и составила 1,3\% (65 чел.). Таким образом, в Саратовской области прослеживается зафиксированная в обшероссийских исследованиях тенденџия улучшения образовательного уровня мунищипальных служащих, а именно, увеличение числа служащих с высшим образованием.

Изменениям подвергаются не только количественные показатели, но и содержательная направленность профессиональной подготовки муниципальных кадров: направление подготовки / специальность «Государственное и муниципальное управление» в 2018 г. имели 6,2\% служащих, высшее образование в сфере экономики, финансов - 26,4\% служащих, в сфере юриспруденщии 16,9\% (табл. 6). Интересным амя анализа представмяется тот факт, что по «традиционным» дмя замешения должностей муниципальной службы направцениям подготовки / специальностям сложкилась отриџательная динамика в сравнении с предыдущим периодом, тогАа как в отношении высшего образования по иным специальностям / направлениям подготовки она положительная. Аомя таких служащих в 2018 г. составияа уже 50,5\% против 41,4\% в 2017 г. 
Таблица 6

Аинамика структуры направлений образования среди муниципальных скужащих в Саратовской обмасти, \%

\begin{tabular}{c|c|c|c|c}
\hline Год & $\begin{array}{c}\text { Экономический } \\
\text { профиль }\end{array}$ & $\begin{array}{c}\text { Юридический } \\
\text { профиль }\end{array}$ & $\begin{array}{c}\text { Государственное } \\
\text { и муниципальное } \\
\text { управление }\end{array}$ & Иное \\
\hline 2016 & 30,35 & 17,52 & 7,63 & 44,50 \\
2017 & 32,20 & 18,50 & 7,90 & 41,40 \\
2018 & 26,40 & 16,9 & 6,2 & 50,5
\end{tabular}

Среди глав муниципальных образований значительная доля Аищ с высшим образованием - 88\%, и только $12 \%$ со средним профессиональным образованием. В разрезе специальностей здесь мидирует экономическое и юридическое образование - 17,6 и 11,1\% соответственно. Профильное образование в сфере пубцичного управления в анализируемом периоде имели только $4 \%$ глав, а 5,55\%, или 18 человек, - два и более высших образования. Можно утверждать, что уровень научных знаний в области муниципального управления среди муниципальных служаших по-прежннему остается невысоким. Следовательно, основным способом формирования управленческих компетенций у служаших в настоящее время явмяется получение дополнительного профессионального образования.

Из 93 муниципальных служащих, прошедших обучение по программам Аополнительного образования в 2018 г., профессиональную переподготовку за счет средств местного бюджета прошии 65 сотрудников $(2,3 \%)$, за счет иных источников - 28 чел. $(0,7 \%)$. На программах повышения квамификации обучились 402 чел. (10\%), в том числе 336 чел. (6,7\%) - за счет средств местного бюджета, 66 чел. (3,3\%) - за счет иных источников. Необходимо обратить внимание на уменьшение количества муниципальных служаших, прошедших повышение квалификации в 2018 г. по сравнению с 2017 г. - на 0,2\%, тогда как объем средств, потраченных на образование муниципальных служащих, значительно вырос - с 1539,6 тыс. рублей в 2017 г., Ао 3068,2 тыс. рублей в 2018 г., то есть в два раза (табл. 7).

Таблица 7

Аанные о муниципальных служащих, прошедших АПО

(в форме повышения квалификации) и объеме средств, потраченных на их образование

\begin{tabular}{c|c|c}
\hline Год & $\begin{array}{c}\text { Число служащих, прошедших } \\
\text { повышение квалификации, чел. }\end{array}$ & $\begin{array}{c}\text { Средства, потраченные } \\
\text { на образование служащих, тыс. руб. }\end{array}$ \\
\hline 2015 & 642 & 783,6 \\
2016 & 266 & 111 \\
2017 & 415 & 1539,6 \\
2018 & 402 & 3068,2
\end{tabular}

22 Bulletin of the Volga Region Institute of Administration 2019. Vol. 19. № 6 
С 2014 г. многие субъекты РФ проводят работу с кадровым потенциалом муниџипальных органов власти как мероприятия подпрограмм. Например, в Алтайском крае это подпрограмма 3 «Совершенствование кадрового обеспечения государственного и муниципального управления А^тайского края» программы «Совершенствование государственного и муниципального управмения в Алтайском крае» [5], в Пензенской области - подпрограмма 3 «Государственная подлержкка развития местного самоуправления в Пензенской области на 2014-2022 годы» программы «Региональная политика, развитие гражданского общества в Пензенской области на 2014-2022 годы» [6]. Свидетельством того, что региональные органы власти уделяют внимание повышению квалификаџии муниципальных служащих, явмяется наличие в подпрограммах цемевого показателя доли муниџипальных служащих, прошедших ежегодное обучение по программам дополнительного профессионального образования, от общей численности муниципальных служащих региона.

В Саратовской области задача по подлержке развития каАрового потенџиала местного самоуправления выполняется в рамках реализаџии двух подпрограмм региональной программы «Развитие государственного и муниципального управления Ао 2020 года» - «Развитие местного самоуправления в Саратовской области до 2020 года», «О дополнительном профессиональном образовании миџ, включенных в управленческий кадровый резерв Саратовской области». Эффективность реализации подпрограмм оџенивается по следующим критериям: 1) «домя муниџипальных служащих в администращиях мунищипальных образований обцасти, проходивших переподготовку и (ими) повышение квалификации не реже одного раза в три года»; 2) «домя специалистов, участвующих в Аеятельности государственных органов власти Саратовской обцасти, от общего числа специалистов, входящих в состав резерва управленческих каАров» соответственно [7]. В то же время, по Аанным табц. 7, из регионального бюАжета финансирование получения муниципальными служащими дополнительного профессионального образования практически не осуществмяется, и, в основном это нагрузка муниципальных бюджетов. Несмотря на рост расходов на обучение муниципальных служащих, недостаточность собственной финансовой базы муниципалитетов не позволяет им осуществлять в полном объеме финансирование программ дополнительного профессионального образования и способствовать профессиональному развитию муниципальных служащих.

На фоне роста доли муниципальных служащих, оплачивающих дополнительное профессиональное образование за счет собственных средств, можно заявцять о формировании тенденџии к осознанию ими значимости дополнительного профессионацьного образования. С одной стороны, это может быть вызвано заинтересованностью сохранить рабочее место, особенно ярко проявАяющейся в сельской местности, гАе возможности трудоустройства ограничены, с Аругой стороны - свидетельствовать о понимании служащими своих «слабых» мест, пробелов в знаниях, несформированности компетенций. Согласно ч. 5 ст. 12 Федерального закона от 2 марта 2007 г. № 25-Ф3 «О муниципальной службе в Российской Федерации» служаший обязан поддерживать свою квалификацию на уровне, необходимом дмя надмежащего исполнения 
функционала по должности, и вправе рассчитывать на финансовую подеержку со стороны местного бюджета, что установлено ч. 7 ст. 11 того же Закона [8]. В реальной практике приходится констатировать, что субъекты Федераџии и муниџипальные образования в большинстве случаев не в состоянии обеспечить еАинство требований к подготовке каАров Аля муниџипальной и гражАанской службы и дополнительному профессиональному образованию в силу дотационности региональных и муниципальных бюджетов.

По мнению представителей кадровых служб и руководящего звена муниципальных образований Саратовской области, в числе факторов, снижающих эффективность муниџипальной кадровой политики, ключевое место занимает финансовая необеспеченность местных бюАжетов. Как слеАствие этой проблемы муниципалитеты имеют недостаточную материально-техническую базу, устаревшее малофункциональное оборудование, ограниченные возможности в сфере совершенствования профессионального уровня служащих. Существенным ограничением в процессе подбора кадров можно считать низкую заинтересованность граждан в поступлении на мунищипальную службу. Особо остро обозначены пробцемы мотиваџии и материального стимулирования служащих, недостаточности перспектив карьерного роста, низкого престижа данного вида деятельности. Об этом свидетельствуют не только результаты опроса на территории Саратовской области, но и, например, отчеты Ассоциации сибирских и дальневосточных городов.

Исследование кадрового потенџиала мунищипальной службы, проведенное в Саратовской области, свидетельствует об отсутствии у муниџипальных образований собственных ресурсов дмя нивелирования конфмикта межАу взаимоисключающими требованиями проводимой муниџипальной реформы. Развитие потенциала муниципальной службы прежде всего зависит от состояния нормативной правовой базы. В 2018 г. в соответствии с задачами социально-экономического развития Российской Федераџии внесены некоторые изменения и дополнения в законодательство о муниципальной службе как на федеральном, так и на региональном уровне. Так, согласно Федеральному закону от 27 декабря 2018 г. № 559-Ф3 «О внесении изменений в статью 7 Федерального закона "Об общих принџипах организаџии и деятельности контрольно-счетных органов субъектов Российской Федераџии и муниџипальных образований" и статью 13 Федерального закона "О муниципальной службе в Российской Федерации”» введено дополнительное ограничение, связанное с назначением на Аолжности преАседателя, заместителя председателя и аудитора контрольно-счетного органа муниципального образования. В частности, на указанные должности не может быть назначен гражданин и / или муниципальный служащий, находящийся в близком родстве или свойстве с главой муниџипального образования, председателем преАставительного органа, главой местной администрации, руководителями правоохранительных и судебных органов, находящихся на территории конкретного муниџипального образования [9] . В Закон Саратовской обцасти от 2 августа 2007 г. № 157-3СО «О некоторых вопросах муниџипальной службы Саратовской области» в 2018 году внесены изменения, направленные на продление срока применения взыска- 
ния за коррупционное правонарушение, что свидетельствует об актуальности работы по созданию условий, искиючающих возможность коррупџионного поведения муниципальных служащих. Эффективность совершенствования правового регулирования муниџипацьной службы зависит от эффективности коммуникации межАу всеми уровнями вцасти и степени использования механизмов законотворческой иниџиативы муниџипальных образований.

Формирование кадрового потенциала муниципацьной службы по установменным законом приоритетным направлениям осуществляется посреАством следующих кадровых технологий: конкурсного отбора; аттестации; использовании кадрового резерва. В то же время обязательной к применению явцяется только аттестаџия, тогда как Аве Аругие технологии носят характер потенџиальной возможности. По поводу этой правовой нормы в экспертном сообществе сформировацись разцичные точки зрения, в том числе обоснование ее правицьности объективно сложившимся кадровым голодом [10]. Речь идет об отсутствии потенциальных человеческих ресурсов, когда в муниџипальном образовании нет кандидатов на конкурсное замещение вакантных домжностей, не говоря ужке о формировании резерва кадров. На наш взглял, законодательство должно задавать вектор развития общественных отношений, а не фиксировать объективную реальность. Целевое назначение конкурса на замещение вакантной Аолжности и кадрового резерва преАполагает не только формирование профессионального кадрового состава, но и обеспечение права на равный Аоступ к муниципальной службе. Это обстоятельство позволяет утверждать необходимость совершенствования анализируемых норм федерального законодательства, если не в отношении всех муниципальных Аолжностей муниџипальной службы, то в отношении наиболее значимых с точки зрения обеспечения соџиальноэкономического развития муниципального образования.

Аостичь Аинамичных положительных савигов в развитии каАрового потенциала муниципальной службы позволит внедрение инновационных подходов к повышению уровня профессионацизма и компетенции муниципацьных служащих. Такой опыт формируется в Саратовской области органами государственной власти совместно с Ассоциацией муниципальных образований области. Учитывая потребность в постоянном обновлении знаний, в рамках юбилейного года пятнадџатилетия Федерамьного закона от 6 октября 2003 г. «Об общих принципах организации местного самоуправления в Российской ФеАерации» № 131-Ф3 при содействии министерства по делам территориальных образований Саратовской области Ассоциацией был организован просветительский проект «Муниципальный факультет». По замыслу проект представляет собой специально организуемую, постоянно действующую систему пополнения и обновцения практических знаний по значимым вопросам социально-экономического состояния муниципацьных образований, развитию отраслевого законодательства по направцениям деятельности органов местного самоуправления, вовлечению населения в решение вопросов местного значения, кадровой работе. ОАнако эта пиошадка не заменяет повышение квалификации и профессионацьную переподготовку служкащих, а дополняет ее.

Мониторинг кадровых проџессов муниципальной службы как оџеночная технология позволяет, с одной стороны, выявить состояние основных парамет- 
ров кадрового состава органов местного самоуправления региона, с Аругой разработать аАаптированную к потребностям конкретных территорий концепцию каАровой политики в отношении органов местного самоуправления. ОАнако подобные эффекты проявляются в случае регулярного использования этой технологии. При формировании кинейки способов развития каАрового потенциала муниципальной службы субъектам Российской ФеАерации важно учитывать специфику территориальной организации местного самоуправления, а именно площадь региона, удаценность муниципацьных образований от аАминистративного центра субъекта, текучесть кадров органов местного самоуправления. В развитие описанной муниџипацьной практики Аля Саратовской области можно рекомендовать следующее: обеспечить возможность обучения мунищипальных служащих на рабочих местах посреАством мибо проведения

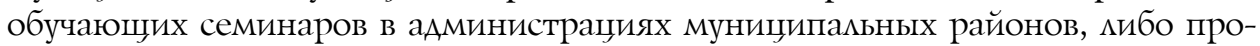
ведения зональных обучающих мероприятий; дмя самостоятельной подготовки служащих применять электронные формы обучения и дистанџионные образовательные технологии; использовать дистанционные формы взаимодействия не только с учебными заведениями, но и с муниципальными служкащими, в том числе и иных органов местного самоуправления дия обмена опытом.

\section{Библиографический список}

1. Боков М.Б. Кадры местного самоуправления: настоящее и будущее // Мониторинг общественного мнения: экономические и социальные перемены. 2009. № 3 (91). С. 51-73.

2. Шамарова Г.М. Формирование и развитие кадрового потенциала органов местного самоуправления: автореф. дис. ... д-ра экон наук. М., 2010.

3. Численность и состав работников, замещавших должности государственной гражданской и муниципальной службы по стажу гражданской и муниципальной службы, по ветвям власти и уровням управления. URL: https://www.gks.ru/folder/11191

4. Основные итоги деятельности в 2018 г. Ассоциация сибирских и дальневосточных городов. URL: https://www.asdg.ru/about/struct/sobr/XXXVI/report2018.pdf

5. Об утверждении государственной программы «Совершенствование государственного и муниципального управления в Алтайском крае»: постановление администрации Алтайского края от 6 марта 2015 г. № 87. URL: http://pravo.gov.ru/proxy/ips/?doc_itself=\&backlink=1\&nd= $168071254 \&$ page $=1 \& \mathrm{rdk}=$

6. Об утверждении государственной программы Пензенской области «Региональная политика, развитие гражданского общества в Пензенской области на 2014-2022 годы»: постановление Правительства Пензенской области от 27 сент. 2013 № 733-пП. URL: http://docs.cntd. $\mathrm{ru} /$ document $/ 423862608$

7. О государственной программе Саратовской области «Развитие государственного и муниципального управления»: постановление Правительства Саратовской области от 20 нояб. 2013 г. (с изм. от 10 сент. 2019 г.) № 647-П. URL: http://docs.cntd.ru/document/467701397

8. О муниципальной службе в Российской Федерации: Федер. закон от 2 марта 2007 г. № 25-Ф3 (в ред. от 27 дек. 2018 г.) // СЗ РФ. 2007. № 10. Ст. 1152.

9. О внесении изменений в статью 7 Федерального закона «Об общих принципах организации и деятельности контрольно-счетных органов субъектов Российской Федерации и муниципальных образований» и статью 13 Федерального закона «О муниципальной службе в Российской Федерации: Федер. закон от 27 дек. 2018 г. № 559-ФЗ // СЗ РФ. 2018. № 53. Ч. І. Ст. 8485.

10. Пресняков М.В., Чаннов С.Е. Проблемы формирования кадрового состава муниципальной службы // Практика муниципального управления. 2009. № 2. С. 96-101. 